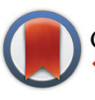

CrossMark $\leftarrow$ click for updates

Cite this: Food Funct., 2016, 7, 4675

Received 1st September 2016

Accepted 5th October 2016

DOI: $10.1039 / \mathrm{c} 6 f \circ 01295 \mathrm{~g}$

www.rsc.org/foodfunction

\section{Bioactive and functional properties of sour cherry juice (Prunus cerasus)}

\author{
Guillermo Cásedas, ${ }^{a}$ Francisco Les, ${ }^{a}$ Maria Pilar Gómez-Serranillos, ${ }^{b}$ Carine Smith ${ }^{c}$ \\ and Víctor López ${ }^{\star a}$
}

Sour cherry juice (Prunus cerasus) is consumed as a nutritional supplement claiming health effects. The aim of the study was to evaluate the different properties of sour cherry juice in terms of antioxidant activity and inhibition of target enzymes in the central nervous system and diabetes. The content of polyphenols and anthocyanins was quantified. Different experiments were carried out to determine the radical scavenging properties of the juice. The activity of sour cherry juice was also tested in physiological relevant enzymes of the central nervous system (acetylcholinesterase, monoamine oxidase A, tyrosinase) and others involved in type 2 diabetes ( $\alpha$-glucosidase, dipeptidyl peptidase-4). Sour cherry juice showed significant antioxidant effects but the activity of the lyophilized juice was not superior to compounds such as ascorbic, gallic or chlorogenic acid. Furthermore, sour cherry juice and one of its main polyphenols known as chlorogenic acid were also able to inhibit monoamine oxidase A and tyrosinase as well as enzymes involved in diabetes. This is the first time that sour cherry juice is reported to inhibit monoamine oxidase A, $\alpha$-glucosidase and dipeptidyl peptidase- 4 in a dose dependent manner, which may be of interest for human health and the prevention of certain diseases.

\section{Introduction}

Cherry belongs to the Rosaceae family, and specifically to the genus Prunus. The most common types of Prunus are Prunus cerasus and Prunus avium, the first one is known as sour cherry and the other is called sweet cherry. Both are considered nutrient dense food with a relatively low caloric content and a significant amount of important nutrients and bioactive food components. ${ }^{1}$ Several studies have confirmed that eating a diet rich in fruit is related to a reduced risk of oxidative stress, cardiovascular disease, cancer, neurodegenerative disorders and diabetes. ${ }^{2-6}$ This may be due to dietary polyphenols, which are formed by at least one aromatic ring with one or more hydroxyl groups attached. ${ }^{7}$

Some of the most common dietary polyphenols present in fruits and berries are anthocyanidins, which generate several anthocyanins. These anthocyanins are responsible for the red colour of fruits and the potential antioxidant activity. Although cherry is botanically classified as a stone fruit (drupe) due to the pit in the centre, it has the appearance of a berry. Several

${ }^{a}$ Department of Pharmacy, Faculty of Health Sciences, Universidad San Jorge, 50.830 Villanueva de Gállego, Zaragoza, Spain. E-mail: ilopez@usj.es

${ }^{b}$ Department of Pharmacology, Faculty of Pharmacy, University Complutense of Madrid, Plaza Ramón y Cajal s/n, 28040 Madrid, Spain

${ }^{c}$ Department of Physiological Sciences, Science Faculty, Stellenbosch University, Stellenbosch, South Africa studies in animal models and in human subjects have demonstrated that dietary polyphenols are bioavailable and exert a protective role against oxidative stress and free radical damage. ${ }^{7}$ Antioxidants have the ability to scavenge or to neutralize free radicals, or are necessary to enable other molecules to perform such a function. ${ }^{8}$

There is strong evidence demonstrating that several ROSmediated pathways may be involved in the neurodegenerative diseases, like Alzheimer's disease (AD) and Parkinson's disease (PD). It has been described that the accumulation of iron ions in the brain leads to higher ROS generation, involvement of mitochondrial pathways and to a decrease of endogenous antioxidants levels. Thus, natural antioxidants may prevent neurodegenerative disorders. ${ }^{9}$

Although mechanisms remain unclear, a body of evidence links type-2 diabetes with dementia and neurodegenerative diseases. ${ }^{10}$ One therapeutic approach to treat diabetes is to retard the absorption of glucose via inhibition of enzymes, such as $\alpha$-glucosidase, in the digestive organs. It has been confirmed that $\alpha$-glucosidase activity in vitro can be inhibited by berry extracts, i.e. blueberry, blackcurrant, strawberry, and raspberry rich in polyphenols. ${ }^{11}$ In recent years, there has also been an increasing interest in the ability of dietary factors to treat diabetes via modulating GLP-1 levels. GLP-1 is secreted from enteroendocrine L cells, which are present in the lower small intestine and large intestine, and stimulates insulin secretion in a blood glucose concentration dependent manner. 
GLP-1 is inactivated by dipeptidyl peptidase-4 (DPP-4), a circulating catabolic enzyme, resulting in a rather short half-life of about two minutes in the blood. There are reports that nonnutrient dietary factors such as polyphenols can affect GLP-1 levels. $^{12}$

The aim of this study is to evaluate the bioactive properties of sour cherry juice in terms of antioxidant potential as well as activity in pharmacological targets of neurological diseases and diabetes. Antioxidant and protective effects of the juice have been studied in cellular and cell free systems. Potential inhibition of enzymes with relevant biological properties such as acetylcholinesterase, monoamine oxidase-A, tyrosinase, $\alpha$-glucosidase and dipeptidyl peptidase 4 has also been carried out.

\section{Materials and methods}

\subsection{Reagents and chemicals}

Chemical reagents were acquired through Sigma-Aldrich, Cayman Chemical, Cymit química and Panreac (Spain). Sour cherry juice (Prunus cerasus) from Rabenhorst ${ }^{\circledR}$ was kindly supplied by Natur Import. According to the manufacturer, the juice is $100 \%$ organic, additives free and was obtained by pressing and pasteurization. The juice is bottled into amber bottles (expiration date: 20/01/2017).

\subsection{Sour cherry juice lyophilization}

$330 \mathrm{~mL}$ of Rabenhorst ${ }^{\circledR}$ sour cherry juice were lyophilized using a Genesis VirTis 25 EL lyophilizer (Wizard 2.0 control system) over 7 days. The liquid sample was frozen at $-80{ }^{\circ} \mathrm{C}$ for $2 \mathrm{~h}$ while the lyophilizer was freezing at $-80{ }^{\circ} \mathrm{C}$. Afterwards, the temperature was modified to $-30{ }^{\circ} \mathrm{C}$ for a couple of hours and for $96 \mathrm{~h}$ to $-60{ }^{\circ} \mathrm{C}$. Next transition was to $-40{ }^{\circ} \mathrm{C}$ again $(4 \mathrm{~h})$ and $24 \mathrm{~h}$ to $-60{ }^{\circ} \mathrm{C}$. Finally, temperature reached until $-15^{\circ} \mathrm{C}(7 \mathrm{~h})$ and dried $22 \mathrm{~h}$ at $20^{\circ} \mathrm{C}$. The last $2 \mathrm{~h}$ temperature was fixed at $40{ }^{\circ} \mathrm{C}$. A sticky red residue was obtained and kept at $-20{ }^{\circ} \mathrm{C}$ in a freezer until experiments were done.

\subsection{Phytochemical analyses of lyophilized sour cherry juice}

2.3.1. Total polyphenols quantification. The FolinCiocalteu assay was used to quantify total phenolic compounds in sour cherry juice. $9 \mu \mathrm{L}$ of the sample was mixed with $201 \mu \mathrm{L}$ of the Folin-Ciocalteu reagent. The sample was incubated $5 \mathrm{~min}$ at room temperature and preserved for the light; $90 \mu \mathrm{L}$ of $\mathrm{Na}_{2} \mathrm{CO}_{3}(10 \%)$ was added to the mixture and incubated in the dark at room temperature for $40 \mathrm{~min}$. Absorbance was measured at $752 \mathrm{~nm}$. The standard curve was performed with different concentrations of gallic acid: 1-0.0078 $\mathrm{mg} \mathrm{mL} \mathrm{mL}^{-1}$. The total polyphenol content is expressed as mg GAE (Gallic Acid Equivalents) per $\mathrm{mg}$ lyophilized sour cherry juice. $^{13}$

2.3.2. HPLC-DAD analysis and anthocyanins quantification. Phytochemical screening of sour cherry juice was performed by HPLC using an Agilent 1260 Infinity LC (column
Eclipse plus C18 $4.6 \times 100 \mathrm{~mm}, 5 \mu \mathrm{m}$ ) equipped with a photodiode array detector. A two-phase gradient system of trifluoroacetic acid/water $(0.5 / 99.5, \mathrm{v} / \mathrm{v})$ as mobile phase $\mathrm{A}$ and trifluoroacetic acid/acetonitrile/water (0.5/50/49.5, v/v) as mobile phase B was used. ${ }^{14}$ The gradient started at $92 \%$ of mobile phase A and $8 \%$ of phase $\mathrm{B}$, reaching $18 \%$ mobile phase $\mathrm{B}$ at $1.2 \mathrm{~min}, 32 \%$ at $14 \mathrm{~min}, 60 \%$ of mobile phase B at $28 \mathrm{~min}$ and $100 \%$ at $34 \mathrm{~min}$, at isocratic elution until $38.8 \mathrm{~min}$. The gradient reached the initial conditions at 39.2 min and was maintained at isocratic elution for $0.8 \mathrm{~min}$. Elution was carried out

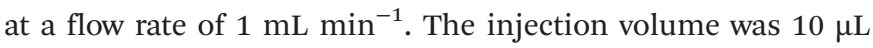
and the concentration of the sample (lyophilized juice) was $100 \mathrm{mg} \mathrm{mL}{ }^{-1}$. Ascorbic acid, gallic acid, ellagic acid, chlorogenic acid, catechin, as well as anthocyanosides were used as standards in order to detect and compare peaks in sour cherry juice. Standards were dissolved in methanol and calibration curves were calculated. Lyophilized juice was dissolved in ultrapure water and filtered with nylon filters of $0.22 \mu \mathrm{m}$ in order to remove any solid residue. For the detection of compounds, the chromatograms were recorded at 260, 280, 320, 360 and $520 \mathrm{~nm}$. Polyphenols were identified according to retention times of standard pure compounds, elution order and comparing with a bibliographic revision of main phenolic compounds. Total anthocyanins were also quantified by HPLC at $520 \mathrm{~nm}$ using cyanidin 3-o-rutinoside (keracyanin chloride) as the standard for a calibration curve.

\subsection{Cytotoxicity screening in HeLa cells}

HeLa cells were used to perform a cell viability test (MTT assay). ${ }^{15}$ HeLa cells were grown in DMEM supplemented with $10 \%$ fetal bovine serum and 1\% penicillin-streptomycin-glutamine. Cultures were incubated in the presence of $5 \% \mathrm{CO}_{2}$ at $37{ }^{\circ} \mathrm{C}$ under a $100 \%$ relative humidified atmosphere. Cells were seeded in 96-well microplates at a density of $7 \times 10^{3}$ cells per well and grown for $24 \mathrm{~h}$ at $37^{\circ} \mathrm{C}$. Cells were then treated with various concentrations of lyophilized sour cherry juice (0.001-1 $\left.\mathrm{mg} \mathrm{mL}^{-1}\right)$ for $72 \mathrm{~h}$ and a MTT solution was added and incubated for $3 \mathrm{~h}$ at $37^{\circ} \mathrm{C}$. Cell survival was measured as the reduction of MTT into formazan at $550 \mathrm{~nm}$ in a microplate reader. Experiments were performed twice.

\subsection{Antioxidant activity assays}

2.5.1. Protective effects of sour cherry juice against hydrogen peroxide induced toxicity in Artemia salina. Dried cysts of Artemia salina were hatched in seawater with aeration for a whole week. Lyophilized cherry juice was dissolved in seawater and transferred to a 6-well plate at different concentrations (250, 500 and $\left.1000 \mu \mathrm{g} \mathrm{mL}{ }^{-1}\right)$ in $5 \mathrm{~mL}$ seawater with 10 nauplii in each well. Control wells were filled with $5 \mathrm{~mL}$ seawater and 10 nauplii also. After $24 \mathrm{~h}$ incubation at room temperature, survival viability was calculated.

As the viability of Artemia salina nauplii was not affected by different concentrations of sour cherry juice, the experiment was performed adding hydrogen peroxide to the wells at a concentration of $0.4 \mathrm{~g} \mathrm{~L}^{-1}$. Two different control wells without sour cherry juice were also set, one with hydrogen peroxide 
and another with seawater. The viability of the nauplii study was measured every $24 \mathrm{~h}$ for $72 \mathrm{~h}^{12}$

2.5.2. Superoxide radical scavenging activity. Sour cherry juice was tested in the xanthine/xanthine oxidase assay in order to measure the capacity to scavenge superoxide radicals. ${ }^{16} 90 \mu \mathrm{M}$ xanthine, $16 \mathrm{mM} \mathrm{Na}_{2} \mathrm{CO}_{3}$, and $22.8 \mu \mathrm{M}$ NBT were dissolved in phosphate buffer $\mathrm{pH}=7$ to reach a volume of $240 \mu \mathrm{L}$. Then, $30 \mu \mathrm{L}$ of sample and $30 \mu \mathrm{L}$ of xanthine oxidase $\left(168 \mathrm{U} \mathrm{L}^{-1}\right)$ were added to start the reaction. The mixture was incubated for $2 \mathrm{~min}$ at $37^{\circ} \mathrm{C}$. Absorbance was measured at $560 \mathrm{~nm}$ and the activity of cherry juice was determined by checking the transformation of NBT to the blue chromogen dye by the superoxide radical $\left(\mathrm{O}_{2}{ }^{-}\right)$. Decreased absorbance of the reaction mixture indicated increased superoxide anion scavenging activity. Gallic acid was used as a reference compound.

2.5.3. Antiradical activity against 2,2-diphenyl-1-picrylhydrazyl (DPPH) radicals. This assay is based on the measurement of the scavenging capacity of antioxidants. ${ }^{17}$ The odd electron of the nitrogen atom in DPPH is reduced by receiving a hydrogen atom from antioxidants to the corresponding hydrazine. $150 \mu \mathrm{L}$ of a DPPH methanolic solution were added to $150 \mu \mathrm{L}$ of different sour cherry juice concentrations dissolved in $\mathrm{MeOH}$. Absorbance was measured at $517 \mathrm{~nm}$ after $30 \mathrm{~min}$ of reaction in a microplate reader. Controls contained a DPPH solution and the solvent. Radical scavenging capacity was calculated by the formula: RSC $(\%)=\left[\left(\mathrm{Abs}_{\mathrm{control}}-\right.\right.$ $\left.\mathrm{Abs}_{\text {sample }} / \mathrm{Abs}_{\text {control }}\right] \times 100$. Ascorbic, gallic and chlorogenic acids were also measured to compare with sour cherry juice antioxidant activity.

\subsection{Bioassays regarding CNS enzymes}

2.6.1. Acetylcholinesterase (AChE) inhibition. The Ellman's method was selected to perform the experiment using a 96-microplate reader. ${ }^{18}$ Each well contained $25 \mu \mathrm{L}$ of $15 \mathrm{mM}$ ATCI in Millipore water, $125 \mu \mathrm{L}$ of $3 \mathrm{mM}$ DTNB in buffer $\mathrm{C}$ (50 mM Tris- $\mathrm{HCl}, \mathrm{pH}=8,0.1 \mathrm{M} \mathrm{NaCl}, 0.02 \mathrm{M} \mathrm{MgCl}_{2} \cdot 6 \mathrm{H}_{2} \mathrm{O}$ ), $50 \mu \mathrm{L}$ buffer $\mathrm{B}$ (50 mM Tris- $\mathrm{HCl}, \mathrm{pH}=8,0.1 \%$ bovine serum), $25 \mu \mathrm{L}$ juice in buffer A ( $50 \mathrm{mM}$ Tris- $\mathrm{HCl}, \mathrm{pH}=8)$. Finally, $25 \mu \mathrm{L}$ of the enzyme $\left(0.22 \mathrm{U} \mathrm{L}^{-1}\right)$ was added to start the reaction. Absorbance was read 13 times every $13 \mathrm{~s}$ at $405 \mathrm{~nm}$. Galantamine was used as the reference substance.

2.6.2. Monoamine oxidase A (MAO-A) inhibition. The activity was measured in a 96-well microplate using a described procedure. ${ }^{19}$ Each well contained $50 \mu \mathrm{L}$ of sour cherry juice in MilliQ water, $50 \mu \mathrm{L}$ chromogenic solution (0.8 mM vanillic acid, $417 \mathrm{mM}$ 4-aminoantipyrine and $4 \mathrm{U} \mathrm{mL}^{-1}$ horseradish peroxidase in potassium phosphate buffer $\mathrm{pH}=7.6), 100 \mu \mathrm{L}$ of $3 \mathrm{mM}$ tyramine and $50 \mu \mathrm{L}$ of $8 \mathrm{U} \mathrm{mL}^{-1}$ MAO-A. Control wells contained $50 \mu \mathrm{L}$ of solvent instead of sour cherry juice. The absorbance was read at $490 \mathrm{~nm}$ every $5 \mathrm{~min}$ for $30 \mathrm{~min}$. Clorgyline was used as the reference substance.

2.6.3. Tyrosinase (TYR) inhibition. The assay was conducted in 96-well microplates using a microplate reader to measure absorbance at $475 \mathrm{~nm} .^{20} 10 \mu \mathrm{L}$ of cherry juice in MilliQ water, $40 \mu \mathrm{L}$ of L-DOPA, $80 \mu \mathrm{L}$ phosphate buffer, $\mathrm{pH}=$
6.8 and $40 \mu \mathrm{L}$ of tyrosinase were mixed in each well. Controls contained $50 \mu \mathrm{L}$ of solvent instead of sour cherry juice. $\alpha$-Kojic acid was used as the reference substance.

\subsection{Bioassays regarding enzymes involved in type 2 diabetes}

2.7.1. Inhibition of $\boldsymbol{\alpha}$-glucosidase ( $\boldsymbol{\alpha}$-GLU). The capacity of sour cherry juice to inhibit $\alpha$-glucosidase was measured in a 96-well microplate reader at $405 \mathrm{~nm} .^{21}$ Each well contained $50 \mu \mathrm{L}$ sample and $100 \mu \mathrm{L}$ enzyme. After $10 \mathrm{~min}, 50 \mu \mathrm{L}$ pNPG were added and incubated at $37^{\circ} \mathrm{C}$ for $20 \mathrm{~min}$. Control wells contained $50 \mu \mathrm{L}$ of solvent (Millipore water) instead of lyophilized juice. Acarbose was used as the reference compound.

2.7.2. Inhibition of dipeptidyl peptidase-4 (DPP-4). The capacity of sour cherry juice and its reference compounds to inhibit the enzyme DPP-4 was measured using the fluorogenic substrate Gly-Pro-Aminomethylcoumarin (AMC) with a commercial kit (Cayman, item no. 700210). The authors followed the kit instructions. Sour cherry juice was tested at four different concentrations $\left(5,1,0.1\right.$ and $0.01 \mathrm{mg} \mathrm{mL}^{-1}$ in the reaction mixture) and sitagliptin as a reference inhibitor of the enzyme. The percentages of inhibition of cherry juice and other compounds were determined with the following formula: $\%$ Inhibition $=[($ Initial Activity - Inhibitor $) /$ Initial Activity $] \times 100$.

\subsection{Statistical analysis}

Results were expressed as the mean \pm standard error of experiments performed in triplicate. GraphPad Prism v. 5 was required to perform data analyses, nonlinear regressions and statistics.

\section{Results}

\subsection{Phytochemical analysis of lyophilized sour cherry juice}

The polyphenol content was measured by the Folin-Ciocalteu method and expressed as gallic acid equivalents (GAE). Sour cherry juice contained $9.835 \pm 1.092 \mu \mathrm{g} \mathrm{GAE} \mathrm{mg}^{-1}$ of lyophilized juice. Five compounds (ascorbic acid, gallic acid, chlorogenic acid, neochlorogenic acid and cyanidin 3-glucosil-rutinoside) out of different monitored polyphenolic compounds were detected, quantified and confirmed comparing retention times and UV spectra with standards (Table 1 and Fig. 1). Total anthocyanins were quantified by HPLC at $520 \mathrm{~nm}$ using cyanidin-3-o-rutinoside (keracyanin chloride) as the external standard following the literature. Anthocyanins were found to be $0.194 \pm 0.004 \mu \mathrm{g}$ cyanidin-3-o-rutinoside equivalents per $\mathrm{mg}$. However, more anthocyanins different from cyanidin 3-glucosilrutinoside might be responsible for the red colour as other minor peaks can be seen at $520 \mathrm{~nm}$ (Fig. 1B).

\subsection{Cytotoxicity screening in HeLa cells}

The lyophilized juice showed very mild antiproliferative effects in HeLa cells. Significant differences were detected at concentrations over $0.125 \mathrm{mg} \mathrm{mL}{ }^{-1}$, which indicates that this cell line seems to be partially sensitive to cherry components. Cell viability was approximately $60 \%$ at the highest tested concentration $\left(1 \mathrm{mg} \mathrm{mL}^{-1}\right)$, which means that the juice 
Table 1 Quantification of individual polyphenols in sour cherry juice (Prunus cerasus) by HPLC

\begin{tabular}{ll} 
Compound & $\begin{array}{l}\mu \mathrm{mg}^{-1} \text { of lyophilized } \\
\text { juice (S.E.) }\end{array}$ \\
\hline Ascorbic acid & $0.011(0.003)$ \\
Gallic acid & $0.047(0.001)$ \\
Ellagic acid & - \\
Catechin & - \\
Chlorogenic acid & $0.593(0.001)$ \\
Neochlorogenic acid & $1.580(0.012)$ \\
Cyanidin 3-glucosil-rutinoside & $0.081(0.000)$ \\
Total polyphenols (Folin method) & $9.835 \pm 1.092$ \\
Total anthocyanins (HPLC method) & $0.194(0.003)$ \\
& \\
-: Not detected; S.E. = standard error. &
\end{tabular}

is not considered cytotoxic in this type of cervical cancer cells (Fig. 2).

\subsection{Antioxidant activity assays}

Fig. 3 indicates that sour cherry juice increased the survival of Artemia salina nauplii compared to $0.4 \mathrm{~g} \mathrm{~L}^{-1}$ hydrogen peroxide at 24, 48 and $72 \mathrm{~h}$. Different concentrations of lyophilized juice enhanced survival of nauplii exposed to hydrogen peroxide, reaching more than $90 \%$ at $24 \mathrm{~h}$. At $48 \mathrm{~h}$, survival of nauplii was around $30-50 \%$ and finally, at $72 \mathrm{~h}$ between $10-20 \%$ of the nauplii survived compared to $0 \%$ survival of nauplii exposed to hydrogen peroxide. Significant differences were only obtained at doses of 1000 and $500 \mu \mathrm{g} \mathrm{mL} \mathrm{m}^{-1}$ at $24 \mathrm{~h}$ and $72 \mathrm{~h}$.

Fig. 4 shows the antioxidant effect of the juice compared to a reference standard such as gallic acid on superoxide radicals generated by the xanthine/xanthine oxidase system. $\mathrm{IC}_{50}$ values in this case were $54 \mu \mathrm{g} \mathrm{mL} \mathrm{m}^{-1}$ for sour cherry juice and 0.044 $\mu \mathrm{g} \mathrm{mL}{ }^{-1}$ for gallic acid.

The DPPH radical scavenging effects of sour cherry juice are shown in Fig. 5. The antiradical activity of the juice was compared to gallic, ascorbic and chlorogenic acid. $\mathrm{IC}_{50}$ values were also calculated by nonlinear regression.

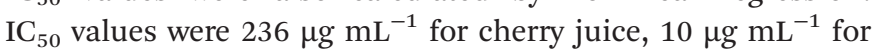
chlorogenic acid, $3 \mu \mathrm{g} \mathrm{mL}^{-1}$ for ascorbic acid and $1 \mu \mathrm{g} \mathrm{mL}^{-1}$ for gallic acid.

All these data indicate that the antioxidant and potential protective effects of sour cherry juice may be due to radical
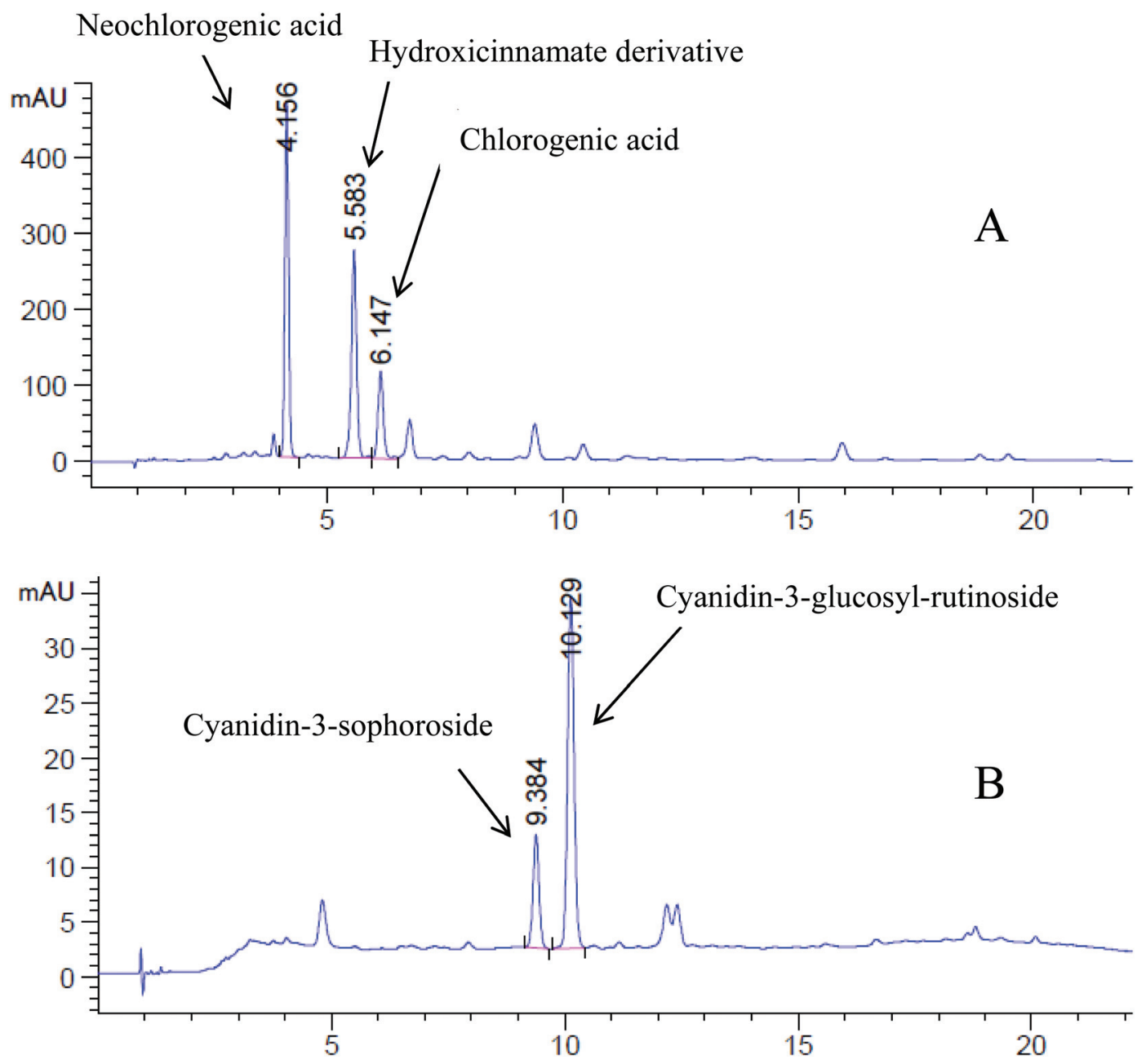

Fig. 1 HPLC chromatograms of lyophilized sour cherry juice at $320 \mathrm{~nm}$ (A) and $520 \mathrm{~nm}$ (B). 


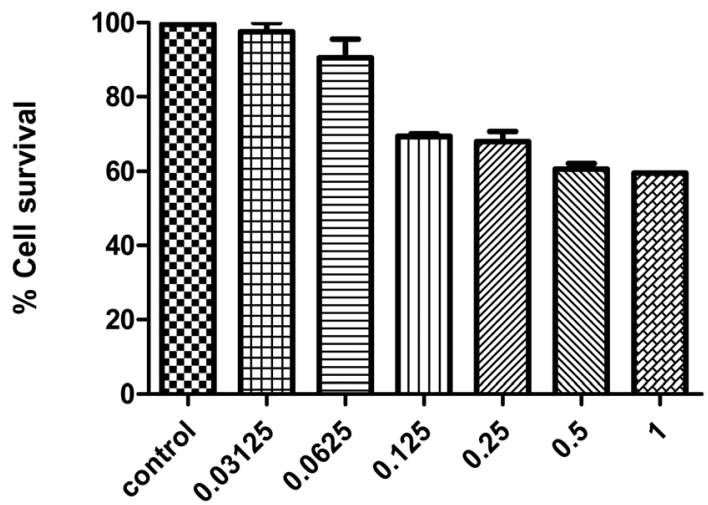

Fig. 2 Viability of HeLa cells exposed to different concentration ( $\mathrm{mg} \mathrm{mL}^{-1}$ ) of sour cherry juice for 72 hours in the MTT assay. $\mathrm{IC}_{50}$ was not calculated as percentages of viability were more than $50 \%$.

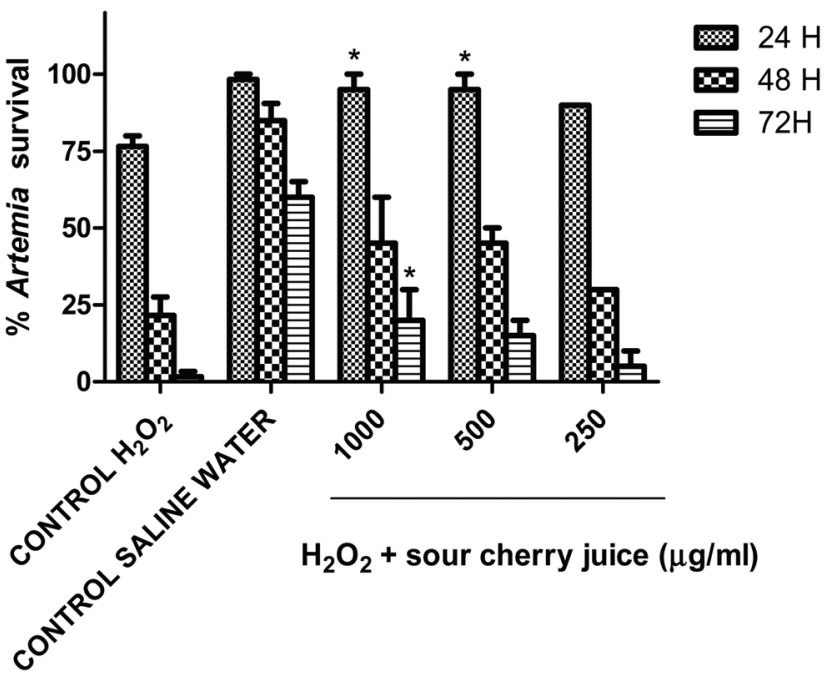

Fig. 3 Effects of sour cherry juice in Artemia salina nauplii exposed to hydrogen peroxide $\left(0.4 \mathrm{~g} \mathrm{~L}^{-1}\right)$. *Significant differences $(p<0.05)$ were detected between nauplii exposed to hydrogen peroxide (control $\mathrm{H}_{2} \mathrm{O}_{2}$ ) and nauplii exposed to hydrogen peroxide $+1000 \mu \mathrm{g} \mathrm{mL}^{-1}$ cherry juice at $24 \mathrm{~h}$ and $72 \mathrm{~h}$. A lower dose of cherry juice $\left(500 \mu \mathrm{g} \mathrm{mL} \mathrm{L}^{-1}\right)$ also showed a protective effect at $72 \mathrm{~h}$. Differences were calculated using Student $t$ tests.

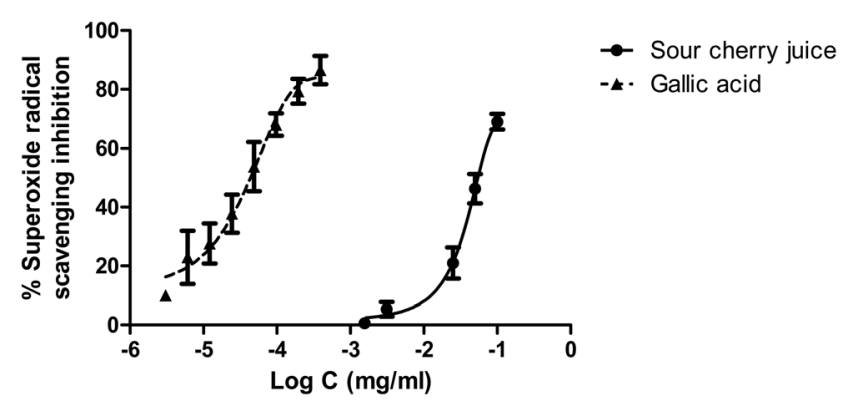

Fig. 4 Antioxidant activity of sour cherry juice and gallic acid against superoxide radicals generated by the xanthine/xanthine oxidase system.

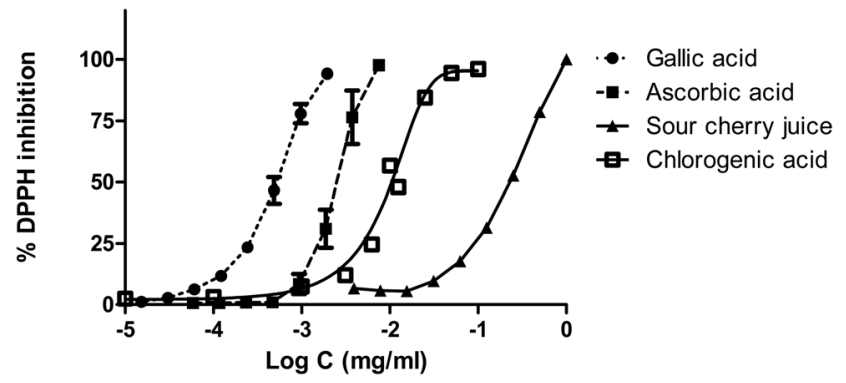

Fig. 5 Antiradical activity of sour cherry juice, ascorbic acid, gallic acid and chlorogenic acid against DPPH.

scavenging properties as it has been demonstrated through the DPPH and superoxide radical assays. In addition, the presence of polyphenols such as chlorogenic acid and anthocyanins in the juice, which was confirmed in the phytochemical analyses, seems to be crucial for the antioxidant and antiradical activities.

\subsection{Bioassays regarding CNS enzymes}

Sour cherry juice did not show activity in the AChE assay; however, it showed a clear dose dependent MAO-A inhibitory activity. These inhibitions are shown in Fig. $6 . \mathrm{IC}_{50}$ values were calculated by nonlinear regression $\left(0.02 \mu \mathrm{g} \mathrm{mL}{ }^{-1}\right.$ for the selective inhibitor clorgyline, $246.19 \mu \mathrm{g} \mathrm{mL}{ }^{-1}$ for sour cherry juice). TYR inhibitory activity was not as clear as for MAO-A. Sour cherry juice produced a very mild inhibition $\left(28 \%\right.$ at $\left.1 \mathrm{mg} \mathrm{mL}^{-1}\right)$ like Fig. 7 shows. In the MAO-A and TYR bioassays, chlorogenic acid showed a higher inhibition than the lyophilized juice.

\subsection{Bioassays regarding type 2 diabetes enzymes}

Sour cherry juice exhibited in vitro an inhibition of $\alpha$-GLU, but this activity was moderate compared to chlorogenic acid and acarbose, which is a reference inhibitor of this enzyme. As shown in Fig. 8, $\mathrm{IC}_{50}$ values were calculated by nonlinear regression $\left(2783 \mu \mathrm{g} \mathrm{mL} \mathrm{m}^{-1}\right.$ for sour cherry juice, $996 \mu \mathrm{g} \mathrm{mL}^{-1}$ for chlorogenic acid and $380 \mu \mathrm{g} \mathrm{mL}^{-1}$ for acarbose).

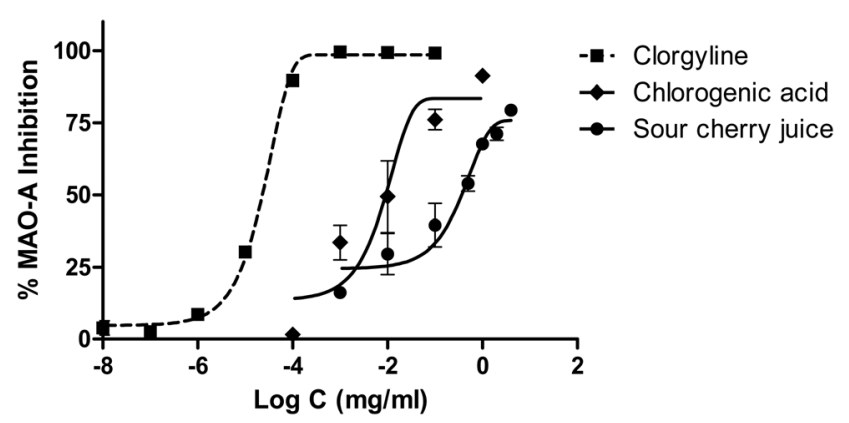

Fig. 6 MAO-A inhibition performed by sour cherry juice, chlorogenic acid and clorgyline. 


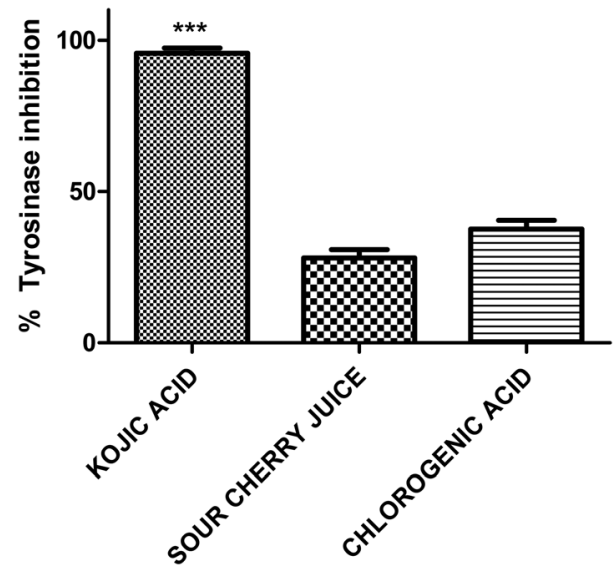

Fig. 7 Tyrosinase inhibition performed by sour cherry juice $\left(1 \mathrm{mg} \mathrm{mL}^{-1}\right)$, chlorogenic acid $\left(1 \mathrm{mg} \mathrm{mL}^{-1}\right)$ and kojic acid $\left(0.2 \mathrm{mg} \mathrm{mL}^{-1}\right)$ as standard. ${ }^{* * *} p<0.0001$ versus sour cherry juice and chlorogenic acid (One way ANOVA with post-hoc Tukey test).

Sitagliptin, an antidiabetic drug, showed a clear dose dependent DPP-4 inhibition. In addition, the effects of the juice and chlorogenic acid in this enzyme are shown in Fig. 9. $\mathrm{IC}_{50}$ values were calculated by nonlinear regression $\left(0.1 \mu \mathrm{g} \mathrm{mL} \mathrm{m}^{-1}\right.$ for sitagliptin and $1003.41 \mu \mathrm{g} \mathrm{mL}^{-1}$ for sour cherry juice) (Fig. 9).

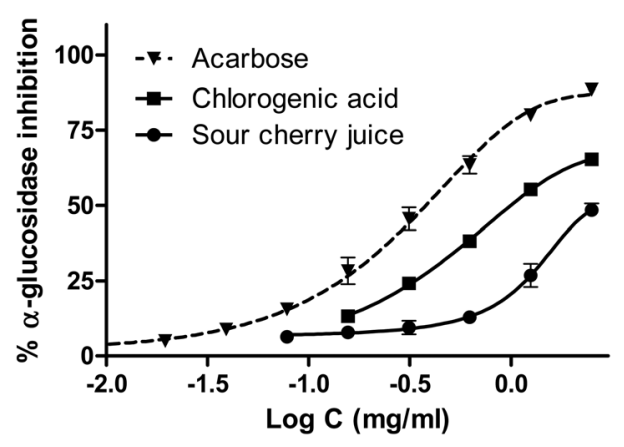

Fig. $8 \alpha$-Glucosidase inhibition performed by sour cherry juice, chlorogenic acid and acarbose as the standard.

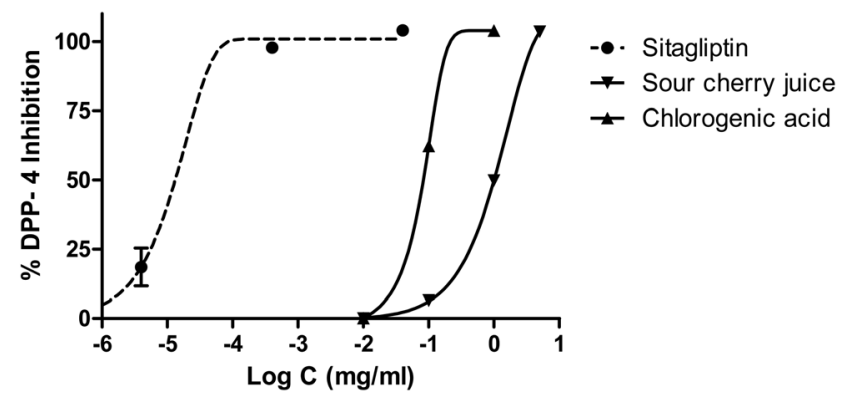

Fig. 9 Dipeptidyl peptidase-4 inhibition performed by sour cherry juice, chlorogenic acid and sitagliptin as the standard.

\section{Discussion}

Sour cherry juice is a good source of phytochemicals, specifically polyphenols and anthocyanins, which are the polyphenols responsible for the red skin and flesh colour. ${ }^{22}$

The concentration of total phenolics (TP) was 9.835 \pm $1.092 \mu \mathrm{g}$ GAE per mg of lyophilized sour cherry juice (approx. $100 \mathrm{mg}$ per $100 \mathrm{~g}$ ), which is a lower concentration compared to other juices such as pomegranate ${ }^{13}$ but can still be of significant importance to produce health benefits. HPLC-DAD analysis showed a peak of chlorogenic acid and previous studies reveal that hydroxycinnamates such as caffeoylquinic acids are the main polyphenols in sweet and sour cherries. ${ }^{22}$ Anthocyanins were also quantified by HPLC-DAD, obtaining approximately $20 \mathrm{mg}$ per $100 \mathrm{~g}$. Other authors such as Wojdyło et al. compared 33 types of sour cherry in terms of the polyphenol content and antioxidant activity; ${ }^{23}$ our results are within the range of anthocyanins calculated for different cherry cultivars (7.56-94.20 mg per $100 \mathrm{~g}$ ) although the authors studied the fruit content instead of juices as in our case.

Sour cherry juice is used in sports medicine to prevent muscle damage as some studies have shown that this product is able to prevent these symptoms through anti-inflammatory and antioxidant properties. ${ }^{24-29}$ Our results confirm the antioxidant potential of sour cherry juice. The protective effects against toxicity induced by hydrogen peroxide were measured using living organisms (Artemia salina). This experiment was performed by the authors using lyophilized sour cherry juice as a co-treatment with hydrogen peroxide and the study demonstrated significant differences of 1000 and $500 \mu \mathrm{g} \mathrm{mL}$ at $24 \mathrm{~h}$ and $1000 \mu \mathrm{g} \mathrm{mL} \mathrm{m}^{-1}$ at $72 \mathrm{~h}$. The juice was also able to scavenge both DPPH and superoxide radicals. It can be deduced that the antioxidant activity is mainly provided by polyphenols such as chlorogenic acid and anthocyanins. Other studies quantified Prunus cerasus antioxidant capacity using trolox as the standard, which makes it difficult to compare with our results. ${ }^{30}$

In addition, the study of the activity of sour cherry juice on enzymes was divided into two main groups, one related to the central nervous system and the other to glucose metabolism. We found for the first time that sour cherry juice was able to inhibit MAO-A and TYR. MAO-A is involved in the deamination of catecholamines and serotonin and certain polyphenols such as anthocyanins are involved in this inhibition, which can drive an antidepressant and anxiolytic effect. ${ }^{31}$ Tyrosinase is a copper-containing enzyme essential for tyrosine-melanin pigmentation and the role of toxic quinones in dopamineinduced neuronal damage catalyzed by TYR has been cleared in a number of studies. ${ }^{32}$ According to our data, this juice may have potential as a neuroprotective agent via MAO-A or TYR inhibition; in fact, a recent interventional human study showed that the consumption of anthocyanin-rich cherry juice for 12 weeks improves memory and cognition in older adults with mild-to-moderate dementia. ${ }^{33}$

Finally, the inhibition of enzymes involved in glucose metabolism and type 2 diabetes was studied; this is the first 
time that sour cherry juice is reported to inhibit $\alpha$-glucosidase and DPP-4 in a dose dependent manner. The anthocyanin content in fruits is also related with $\alpha$-glucosidase inhibition. ${ }^{34}$ According to our results, chlorogenic acid is also responsible for the activity. Polyphenols have also shown to facilitate the insulin response and attenuate secretion of glucose-dependent insulinotropic polypeptide and GLP-1. The DPP-4 enzyme also regulates glycaemia and its inhibitors such as sitagliptin represent some of the new treatments for type 2 diabetes. Taking in consideration that type 2 diabetes is linked to neurodegenerative diseases due to the production of superoxide radicals, sour cherry (Prunus cerasus) juice might be an interesting antioxidant nutritional tool to prevent these disorders.

\section{Conflicts of interest}

The authors declare that they do not have any conflicts of interest.

\section{Acknowledgements}

Universidad San Jorge is acknowledged for financial support and providing Guillermo Casedas and Francisco Les PhD grants. Dr Olga Abian (IACS, BIFI-Universidad de Zaragoza) is thanked for providing HeLa cells. Natur Import is acknowledged for supplying the juice and CITA Aragón for lyophilization.

\section{References}

1 L. M. McCune, C. Kubota, N. R. Stendell-Hollis and C. A. Thomson, Cherries and Health: A Review, Crit. Rev. Food Sci. Nutr., 2010, 51(1), 1-12.

2 C. Del Bo', D. Martini, M. Porrini, D. Klimis-Zacas and P. Riso, Berries and oxidative stress markers: an overview of human intervention studies, Food Funct., 2015, 6(9), 28902917.

3 L. Wu, D. Sun and Y. He, Fruit and vegetables consumption and incident hypertension: dose-response meta-analysis of prospective cohort studies, J. Hum. Hypertens., 2016, 30(10), 573-580.

4 S. Afrin, F. Giampieri, M. Gasparrini, T. Y. ForbesHernandez, A. Varela-López, J. L. Quiles, B. Mezzetti and M. Battino, Chemopreventive and Therapeutic Effects of Edible Berries: A Focus on Colon Cancer Prevention and Treatment, Molecules, 2016, 21(2), 169.

5 D. J. Lamport, C. Saunders, L. T. Butler and J. P. Spencer, Fruits, vegetables, $100 \%$ juices, and cognitive function, Nutr. Rev., 2014, 72(12), 774-789.

$6 \mathrm{H}$. Guo and W. Ling, The update of anthocyanins on obesity and type 2 diabetes: experimental evidence and clinical perspectives, Rev. Endocr. Metab. Disord., 2015, 16(1), 1-13.
7 D. Del Rio, A. Rodriguez-Mateos, J. P. E. Spencer, M. Tognolini, G. Borges and A. Crozier, Dietary (Poly)phenolics in Human Health: Structures, Bioavailability, and Evidence of Protective Effects Against Chronic Diseases, Antioxid. Redox Signaling, 2013, 18(14), 1818-1892.

8 R. L. Prior, Fruits and vegetables in the prevention of cellular oxidative damage, Am. J. Clin. Nutr., 2003, 78(3 Suppl.), 570-578.

9 A. Ebrahimi and H. Schluesener, Natural polyphenols against neurodegenerative disorders: Potentials and pitfalls, Ageing Res. Rev., 2012, 11(2), 329-345.

10 G. Verdile, S. J. Fuller and R. N. Martins, The role of type 2 diabetes in neurodegeneration, Neurobiol. Dis., 2015, 84, 22-38.

11 G. J. McDougall, F. Shpiro, P. Dobson, P. Smith, A. Blake and D. Stewart, Different polyphenolic components of soft fruits inhibit $\alpha$-amylase and $\alpha$-glycosidase, J. Agric. Food Chem., 2005, 53(7), 2760-2766.

12 T. Tsuda, Possible abilities of dietary factors to prevent and treat diabetes via the stimulation of glucagon-like peptide-1 secretion, Mol. Nutr. Food Res., 2015, 59(7), 1264-1273.

13 F. Les, J. M. Prieto, J. M. Arbonés-Mainar, M. S. Valero and V. López, Bioactive properties of commercialised pomegranate (Punica granatum) juice: antioxidant, antiproliferative and enzyme inhibiting activities, Food Funct., 2015, 6(6), 2049-2057.

14 M. C. Díaz-García, J. M. Obón, M. R. Castellar, J. Collado and M. Alacid, Quantification by UHPLC of total individual polyphenols in fruit juices, Food Chem., 2013, 138(2-3), 938-949.

15 T. Mosmann, Rapid colorimetric assay for cellular growth and survival: application to proliferation and cytotoxicity assays, J. Immunol. Methods, 1983, 65, 55-63.

16 J. L. Rodríguez-Chávez, E. Coballase-Urrutia, A. NietoCamacho and G. Delgado-Lamas, Antioxidant Capacity of "Mexican Arnica" Heterotheca inuloides Cass Natural Products and Some Derivatives: Their Anti-Inflammatory Evaluation and Effect on C. elegans Life Span, Oxid. Med. Cell. Longevity, 2015, 2015, 843237.

17 V. Lopez, S. Akerreta, E. Casanova, J. M. Garcia-Mina, R. Y. Cavero and M. I. Calvo, In vitro antioxidant and antirhizopus activities of Lamiaceae herbal extracts, Plant Foods Hum. Nutr., 2007, 62, 151-155.

18 I. K. Rhee, M. van de Meent, K. Ingkaninan and R. Verpoorte, Screening for acetylcholinesterase inhibitors from Amaryllidaceae using silica gel thin-layer chromatography in combination with bioactivity staining, J. Chromatogr., A, 2001, 915(1-2), 217-223.

19 H. T. Olsen, G. I. Stafford, J. van Staden, S. B. Christensen and A. K. Jäger, Isolation of the MAO-inhibitor naringenin from Mentha aquatica L, J. Ethnopharmacol., 2008, 117(3), 500-502.

20 F. Sezer Senol, I. E. Orhan, U. Ozgen, G. Renda, G. Bulut, L. Guven, E. S. Karaoglan, H. G. Sevindik, K. SkalickaWozniak, U. Koca Caliskan and N. Sekeroglu, Memoryvitalizing effect of twenty-five medicinal and edible plants 
and their isolated compounds, S. Afr. J. Bot., 2016, 102, 102-109.

21 M. I. Kazeem, J. O. Adamson and I. A. Ogunwande, Modes of inhibition of $\alpha$-amylase and $\alpha$-glucosidase by aqueous extract of Morinda lucida benth leaf, BioMed Res. Int., 2013, 2013, 527570.

22 G. Ferretti, T. Bacchetti, A. Belleggia and D. Neri, Cherry antioxidants: from farm to table, Molecules, 2010, 15(10), 6993-7005.

23 A. Wojdyło, P. Nowicka, P. Laskowski and J. Oszmiański, Evaluation of sour cherry (Prunus cerasus L.) fruits for their polyphenol content, antioxidant properties, and nutritional components, J. Agric. Food Chem., 2014, 62(51), 12332-12345.

24 D. A. Connolly, M. P. McHugh, O. I. Padilla-Zakour, L. Carlson and S. P. Sayers, Efficacy of a tart cherry juice blend in preventing the symptoms of muscle damage, Br. J. Sports Med., 2006, 40(8), 679-683.

25 G. Howatson, M. P. McHugh, J. A. Hill, J. Brouner, A. P. Jewell, K. A. van Someren, R. E. Shave and S. A. Howatson, Influence of tart cherry juice on indices of recovery following marathon running, Scand. J. Med. Sci. Sports, 2010, 20(6), 843-852.

26 K. S. Kuehl, E. T. Perrier, D. L. Elliot and J. C. Chesnutt, Efficacy of tart cherry juice in reducing muscle pain during running: a randomized controlled trial, J. Int. Soc. Sports Nutr., 2010, 7, 17.

27 J. L. Bowtell, D. P. Sumners, A. Dyer, P. Fox and K. N. Mileva, Montmorency cherry juice reduces muscle damage caused by intensive strength exercise, Med. Sci. Sports Exercise, 2011, 43(8), 1544-1551.
28 K. S. Kuehl, Cherry juice targets antioxidant potential and pain relief, Med. Sport Sci., 2012, 59, 86-93.

29 L. Dimitriou, J. A. Hill, A. Jehnali, J. Dunbar, J. Brouner, M. P. McHugh and G. Howatson, Influence of a Montmorency cherry juice blend on indices of exerciseinduced stress and upper respiratory tract symptoms following marathon running-a pilot investigation, J. Int. Soc. Sports Nutr., 2015, 12, 22.

30 J. Cao, Q. Jiang, J. Lin, X. Li, C. Sun and K. Chen, Physicochemical characterisation of four cherry species (Prunus spp.) grown in China, Food Chem., 2015, 173, 855863.

31 S. M. Nabavi, M. Daglia, N. Braidy and S. F. Nabavi, Natural products, micronutrients, and nutraceuticals for the treatment of depression: A short review, Nutr. Neurosci., 2015, DOI: 10.1080/1028415X.2015.1103461.

32 T. Masuda, D. Yamashita, Y. Takeda and S. Yonemori, Screening for tyrosinase inhibitors among extracts of seashore plants and identification of potent inhibitors from Garcinia subelliptica, Biosci., Biotechnol., Biochem., 2005, 69(1), 197-201.

33 K. Kent, K. Charlton, S. Roodenrys, M. Batterham, J. Potter, V. Traynor, H. Gilbert, O. Morgan and R. Richards, Consumption of anthocyanin-rich cherry juice for 12 weeks improves memory and cognition in older adults with mildto-moderate dementia, Eur. J. Nutr., 2015, DOI: 10.1007/ s00394-015-1083-y.

34 G. J. McDougall, F. Shpiro, P. Dobson, P. Smith, A. Blake and D. Stewart, Different polyphenolic components of soft fruits inhibit $\alpha$-amylase and $\alpha$-glycosidase, J. Agric. Food Chem., 2005, 53(7), 2760-2766. 